\title{
Liderança, Coesão e Satisfação em Equipas Desportivas: Um Estudo com Atletas Portugueses de Futebol e Futsal
}

\author{
Leadership, Cohesion and Satisfaction in Sporting Teams: \\ A Study with Portuguese Football and Futsal Athletes
}

\author{
A. Rui Gomes*, Ana Patricia Pereira \& Ana Raquel Pinheiro \\ Universidade do Minho, Braga, Portugal
}

\begin{abstract}
Resumo
Este trabalho foi realizado com 200 atletas de duas modalidades (futebol e futsal) incluídos em vários escalões desportivos e analisa a liderança dos treinadores e a coesão e satisfação dos praticantes. Para tal, utilizámos um protocolo de avaliação, com instrumentos de avaliação da liderança (Escala Multidimensional de Liderança, que avalia seis dimensões), da coesão (Questionário de Coesão em Equipas Desportivas, que avalia quatro dimensões) e da satisfação (Escala de Satisfação, que avalia três dimensões). Os dados de fidelidade e validade dos instrumentos foram muito aceitáveis. Os resultados demonstraram que os homens e as mulheres avaliam e preferem comportamentos distintos nos seus treinadores, observando-se níveis superiores de coesão social nas atletas do sexo feminino. Do mesmo modo, existem variações de acordo com a idade dos atletas na percepção da liderança dos treinadores, sendo também de destacar o facto dos mais novos representarem um grupo com menor coesão. Duas conclusões fundamentais devem ser referidas. Por um lado, o facto das acções dos treinadores produzirem um impacto significativo na experiência desportiva dos atletas e, por outro lado, a necessidade dos técnicos adaptarem os seus comportamentos em função da idade e tipo de atletas que orientam para assim aumentarem a sua eficácia junto das equipas.

Palavras-chave: Liderança; coesão; satisfação; Psicologia do Desporto.
\end{abstract}

\begin{abstract}
This work was done with 200 athletes from 2 types of sports (soccer and futsal) in several competitive levels and it analyzed coaches' leadership styles and athletes' cohesion and satisfaction levels. Evaluation instruments on leadership (Multidimensional Leadership Scale in Sports which assesses six different dimensions), cohesion (Group Environment Questionnaire which assesses four different dimensions) and satisfaction (Satisfaction Scale which assesses three different dimensions) were applied and received good validity and reliability levels. The results showed that men and women evaluated and preferred different coaches' behaviors, and female athletes assumed higher levels of social cohesion. Likewise, variations were found concerning athletes' age on the perceptions of coach leadership; the youngest group presented lower cohesion levels. Two main conclusions must be stated. On one hand, the significant impact of coaches' behaviors in athletes' sport experience and, on the other hand, the need of coaches' leadership adaptation concerning athletes' gender and age in order to enhance their efficacy while working with the teams.

Keywords: Leadership; cohesion; satisfaction; Sport Psychology.
\end{abstract}

O estudo da liderança exercida pelos treinadores em contextos desportivos representa um tema de bastante debate no domínio da Psicologia do Desporto, uma vez que os efeitos produzidos por estes profissionais podem ser observados não só na forma como os atletas encaram e respondem à actividade desportiva mas também ao nível do próprio rendimento desportivo.

Um dos aspectos que pode contribuir para a melhoria do entendimento destes factores prende-se com o desenvolvimento de modelos conceptuais e metodologias de avaliação acerca dos estilos de liderança, observando-se a forma

* Endereço para correspondência: Universidade do Minho, Instituto de Educação e Psicologia, Campus de Gualtar, Braga, Portugal, 4710-057. E-mail: rgomes@ iep.uminho.pt como os treinadores exercem a sua influência nos atletas e no rendimento das equipas. No âmbito da Psicologia do Desporto, uma das propostas teóricas que mais contributos tem fornecido no entendimento da relação entre treinador e atletas é o modelo multidimensional de Chelladurai (1978, 1990, 1993a). De acordo com este autor, quanto mais o treinador conseguir obter uma congruência entre os comportamentos que assume e aqueles que lhe são exigidos pelo contexto e os que são preferidos pelos atletas, maior é a possibilidade de aumentar a satisfação dos praticantes e o rendimento das equipas. Um dos instrumentos de avaliação utilizados neste âmbito é a "Escala de Liderança no Desporto" ("Leadership Scale for Sports" - LSS) de Chelladurai e Saleh (1978, 1980) que avalia cinco dimensões da acção dos responsáveis técnicos (comportamento 
de instrução e treino, comportamento autocrático, comportamento democrático, apoio social e "feedback" positivo). Apesar da sua validade e interesse inegável, esta escala resulta de um modelo do entendimento da liderança que não contempla os avanços mais recentes do estudo deste tema ao nível da Psicologia geral, e que se prendem com as abordagens carismáticas e transformacionais da liderança (ver Bass, 1985, 1990; Burns, 1978; Conger \& Kanungo, 1998; Gomes, Sousa, \& Cruz, 2006; House \& Shamir, 1993). Este novo movimento privilegia o estudo de determinados líderes que apresentam uma capacidade extraordinária para orientar outras pessoas, levando-as a acreditar nas suas capacidades para atingirem níveis de rendimento superiores e influenciando-as na aceitação de novos valores e ideais acerca do trabalho (Gomes \& Cruz, 2006a, 2006b). Os dados das investigações vieram demonstrar que estes líderes alcançavam maior eficácia pessoal e rendimento nas equipas de trabalho e produziam experiências mais positivas de satisfação, comprometimento e coesão nos membros do grupo/organização (ver Avolio \& Bass, 1988; Bass, 1990; Bass \& Avolio, 1997; Brown \& Dodd, 1999; Podsakoff, MacKenzie, Moorman, \& Fetter, 1990).

Foi a partir destes dados que alguns investigadores analisaram a possibilidade destas abordagens serem aplicáveis ao contexto desportivo, nomeadamente a figuras centrais da actividade desportiva, como sejam, os gestores e directores técnicos, os pais dos atletas, etc. (ver Doherty, 1997; Hawkins \& Tolzin, 2002; Yusof, 1998; Zacharatos, Barling, \& Kelloway, 2000). No entanto, apesar destes esforços, é curioso verificar uma escassez de trabalhos centrados no estudo do próprio treinador enquanto fonte de comportamentos carismáticos e transformacionais. Numa tentativa de colmatar esta lacuna, Gomes (2005) propôs a Escala Multidimensional de Liderança no Desporto, que congrega não só os contributos dados no âmbito da Psicologia do Desporto, mas também as indicações resultantes da liderança carismática e transformacional. Neste sentido, o estudo levado a cabo pelo autor, com mais de 1700 atletas portugueses, resultou num instrumento de avaliação com seis domínios da acção dos treinadores (motivação/inspiração, apoio social, comportamento democrático, "laissezfaire", "feedback" positivo e "feedback" negativo).

Sendo este um dos primeiros estudos acerca da liderança transformacional em treinadores, torna-se agora fundamental aprofundar as indicações positivas obtidas com novas investigações centradas na análise da validade do instrumento e nas relações existentes entre os estilos de liderança e determinadas variáveis pessoais e desportivas dos atletas (e.g., sexo, idade, escalão desportivo, satisfação, coesão, etc.).

É neste âmbito que surge este trabalho, procurando esclarecer as facetas de liderança assumidas por treinadores de equipas de duas modalidades desportivas bem como a relação entre algumas variáveis pessoais e desportivas dos atletas e os níveis de coesão e satisfação manifestados. Paralelamente, optamos neste estudo por utilizar duas versões da escala de avaliação dos estilos de liderança, observando-se não só a frequência dos comportamentos dos treinadores, mas também a preferência dos atletas acerca das dimensões da acção dos técnicos. Neste sentido, este trabalho tem também como objectivo adicional colmatar a ainda escassez de investigações realizadas fora da América do Norte, que comparam as dimensões dos comportamentos actuais dos treinadores com os comportamentos mais valorizados pelos atletas.

\section{Método}

\section{Amostra}

Participaram neste estudo 200 atletas, sendo 170 do sexo masculino (85\%) e 30 do sexo feminino (15\%), com idades compreendidas entre os 11 e os 36 anos $(M=16.8$ anos), apresentando entre 1 a 24 anos de prática desportiva $(M=5.9$ anos). Os atletas eram praticantes de futebol e futsal, distribuindo-se por nove equipas nos seguintes escalões: infantis (11 a 12 anos), iniciados (13 a 14 anos), juvenis (15 a 16 anos), juniores (17 a 18 anos) e seniores (mais de 18 anos). No futebol, a distribuição é de uma equipa masculina por cada um dos cinco escalões e no futsal são quatro equipas (uma masculina e outra feminina nos escalões juniores e seniores), perfazendo um total de 147 atletas no futebol $(73.5 \%)$ e 53 no futsal $(26.5 \%)$. Todos os atletas eram praticantes federados, distribuindo-se pelas ligas principais (equipa sénior de futebol) e secundárias das respectivas modalidades (restantes equipas).

\section{Instrumentos Utilizados}

Questionário demográfico. Para além de avaliar variáveis como o sexo, a idade e as habilitações literárias, recolheu dados relativos ao clube, à modalidade de proveniência dos atletas, ao escalão e à divisão competitiva. Paralelamente, procurámos obter algumas informações sobre a carreira desportiva dos atletas (anos de prática e número de internacionalizações).

Escala Multidimensional de Liderança no Desporto (EMLD - versão dos comportamentos actuais e dos comportamentos preferidos). Este instrumento foi desenvolvido por Gomes (2005) e Gomes e Cruz (2006a), sendo constituído por 28 itens incluídos em seis subescalas distintas: (a) "feedback" positivo: comportamentos de reforço e reconhecimento do treinador face ao bom rendimento e esforço dos atletas; (b) motivação/inspiração: comportamentos do treinador no sentido de promover o desejo de sucesso e esforço contínuo dos atletas na realização das tarefas e na concretização dos objectivos, assumindo-se como um modelo a seguir, em termos de optimismo, confiança e respeito; (c) apoio social: comportamentos do treinador orientados para o bem-estar dos atletas, demonstrando uma preocupação pessoal com os problemas dos membros da equipa bem como um interesse em desenvolver relações pessoais francas e informais; (d) comportamento democrático: acções do treinador no sentido de promover um maior envolvimento dos atletas no processo de tomada de decisão, nomeadamente em aspectos relacionados com o treino e a competição; (e) "laissez-faire": evitamento na tomada de decisão e distanciamento dos técnicos face às suas respon- 
sabilidades quando é necessário resolver problemas importantes e (f) "feedback" negativo: comportamentos de punição e castigo no sentido de gerir ou controlar os comportamentos inadequados dos atletas. O número de itens em ambas as versões é o mesmo, alterando-se a forma como os atletas preenchem os instrumentos (e.g., na versão de comportamentos actuais, os itens são apresentados após a frase "O meu treinador...", enquanto que na versão de comportamentos preferidos, os itens são apresentados após a frase "Eu prefiro que o meu treinador..."). Os itens são respondidos numa escala tipo "Likert" com cinco opções de resposta ( $1=$ Nunca; $5=$ Sempre $)$, significando os valores mais altos em cada uma das subescalas maiores frequências de comportamentos por parte do treinador.

Questionário de Coesão em Equipas Desportivas (QCED). A versão utilizada neste estudo foi traduzida e adaptada para os atletas portugueses por Cruz e Antunes (1997) e Cruz e Viana (1993) a partir do questionário desenvolvido originalmente por Carron e pesquisadores (ver Brawley, Carron, \& Widmeyer, 1987; Carron, Brawley, \& Widmeyer, 1998; Carron, Widmeyer, \& Brawley, 1985; Widmeyer, Brawley, \& Carron, 1985). O QCED é constituído por 18 itens distribuídos por quatro dimensões, sendo as afirmações respondidas numa escala tipo "Likert" de nove pontos $(1=$ Discordo totalmente; $9=$ Concordo totalmente). Assim, a (a) integração no grupo (tarefa) procura avaliar os sentimentos individuais dos membros da equipa relativamente à semelhança e proximidade da equipa como um todo quanto às tarefas a realizar; (b) a integração no grupo (social), refere-se aos sentimentos e percepções individuais dos membros da equipa quanto à semelhança e proximidade no interior da equipa como um todo, enquanto unidade social; (c) a atracção individual para o grupo (tarefa), identifica os sentimentos individuais dos membros da equipa acerca do seu envolvimento pessoal com as tarefas, produtividade, metas e objectivos do grupo e, por último, a (d) atracção individual para o grupo (social), reflecte os sentimentos individuais dos membros da equipa relativamente ao seu envolvimento pessoal, aceitação e interacção social com o grupo. As pontuações mais altas em cada uma das subescalas significam valores mais elevados de coesão nesses domínios.

Escala de Satisfação (ES): trata-se de um instrumento desenvolvido por Cruz e Antunes (1997) a partir dos trabalhos de Chelladurai, Imamura, Yamaguchi, Oinuma e Miyauchi (1988), sendo constituído por 15 itens distribuídos por três subescalas: (a) satisfação com a liderança: aponta os sentimentos positivos dos atletas relativamente à liderança do treinador; (b) satisfação com o ambiente e apoio na equipa: descreve as opiniões favoráveis acerca do ambiente de apoio e de relacionamento positivo entre todos; e, (c) satisfação com o rendimento individual: descreve a opinião dos atletas sobre a performance obtida nos treinos e nas competições bem como acerca do estado de forma física. Os itens da Escala de Satisfação são respondidos numa escala tipo "Likert" de sete pontos ( 1 = Extremamente insatisfeito; 7 = Muito satisfeito). Os "scores" de cada dimensão são calculados através da soma dos itens correspondentes a cada subescala, dividindo depois esse valor pelo número total de itens, atendendo-se à cotação invertida dos que são formulados pela "negativa". Os valores mais elevados em cada subescala significam maiores frequências de satisfação, por parte dos atletas, em cada uma das áreas de acção descritas.

\section{Procedimento}

O Questionário que englobava os instrumentos atrás referidos foi distribuído junto de vários atletas, sendo a sua entrega e recolha efectuada num único momento junto das várias equipas. Assim, numa primeira fase foram contactados os treinadores no sentido de transmitirmos os objetivos do estudo e os procedimentos a adoptar na aplicação dos instrumentos. Após a concordância dos mesmos, efectuou-se a deslocação para a recolha dos dados.

O questionário distribuído incluía, anexa, uma carta de apresentação dirigida aos atletas, acerca dos objectivos e implicações da investigação e do carácter voluntário da participação. Todos os participantes que pretendiam obter informações sobre os resultados, deveriam preencher o seu nome e morada para posterior contacto da nossa parte.

\section{Resultados}

\section{Características Psicométricas dos Instrumentos Utilizados}

O tratamento e análise estatística dos dados foram efectuados no programa SPSS (versão 14.0 para Windows) e incluiu vários procedimentos que serão explicados no decorrer do trabalho.

Em primeiro lugar, efectuou-se uma análise factorial de componentes principais, sem pré-definição do número de factores, através da rotação ortogonal (procedimento "varimax"), com normalização de Kaiser ("eigenvalue" igual ou superior a 1). Foram estabelecidos previamente alguns critérios para a definição dos factores finais: (a) saturação igual ou superior a .40 de cada item no factor hipotético e apenas num único factor; (b) aceitação da solução factorial final a partir do momento em que explicasse pelo menos $50 \%$ da variância total; (c) existência de uma coerência entre a solução factorial e os itens que constituem cada um dos factores e (d) cada factor deveria ser representado, pelo menos, por dois itens (ver Gorsuch, 1983; Hair, Anderson, Tatham, \& Black, 1995).

No que respeita à Escala Multidimensional de Liderança no Desporto, os resultados obtidos apontaram a solução final dos seis factores previstos, que permitiram explicar $67.1 \%$ da variância total, distribuindo-se da seguinte forma: motivação/inspiração (24.9\%) $(\alpha=.82$ para a EMLD comportamentos actuais e $\alpha=.86$ para a EMLD comportamentos preferidos), comportamento democrático (15.6\%) ( $\alpha=.84$ para a EMLD comportamentos actuais e $\alpha=.88$ para a EMLD comportamentos preferidos), apoio social (8.9\%) ( $\alpha=.70$ para a EMLD comportamentos actuais e $\alpha=.71$ para a EMLD comportamentos preferidos), "feedback" negativo (6.3\%) $(\alpha=.74$ para a EMLD comportamentos actuais e $\alpha=.78$ para a EMLD comporta- 
Gomes, A. R., Pereira, A. P. \& Pinheiro, A. R. (2008). Liderança, Coesão e Satisfação em Equipas Desportivas: Um Estudo com Atletas Portugueses de Futebol e Futsal.

mentos preferidos), "feedback" positivo (5.9\%) $(\alpha=.74$ para a EMLD comportamentos actuais e $\alpha=.69$ para a EMLD comportamentos preferidos) e "laissez-faire" $(5.5 \%)$ $(\alpha=.67$ para a EMLD comportamentos actuais e $\alpha=.72$ para a EMLD comportamentos preferidos). Esta análise teve por base valores para o $K M O$ de .76 e um nível de significância do teste de esferacidade de Barlett de $p=.00$, significando na prática a possibilidade de aplicar este tipo de procedimento de análise ao instrumento.

No Questionário de Coesão em Equipas Desportivas, tal como era esperado, verificou-se uma estrutura de quatro factores, com uma explicação de $63.6 \%$ da variância total. Mais concretamente, obtiveram-se os seguintes valores pelas dimensões: atracção individual para o grupo (tarefa) com $30.6 \%(\alpha=.72)$, atracção individual para o grupo (social) com $15.1 \%(\alpha=.60)$, integração no grupo (tarefa) com $9.5 \%(\alpha=.69)$ e integração no grupo (social) com $8.4 \%(\alpha=.71)$. Esta análise teve por base valores para o KMO de .77 e um nível de significância do teste de esferacidade de Barlett de $p=.00$, significando na prática a possibilidade de aplicar este tipo de procedimento de análise ao instrumento.

Por último, a Escala de Satisfação apresentou três factores explicadores de $78.5 \%$ da variância total, distribuindo-se do seguinte modo: satisfação com a liderança com $57.3 \%$ ( $\alpha=.96)$, satisfação com o ambiente e apoio na equipa com $13.5 \%(\alpha=.88)$ e a satisfação com o rendimento individual com $7.7 \%(\alpha=.71)$. Esta análise teve por base valores para o KMO de 90 e um nível de significância do teste de esferacidade de Barlett de $p=.00$, significando na prática a possibilidade de aplicar este tipo de procedimento de análise ao instrumento.

Os dados obtidos nas análises efectuadas aos três instrumentos revelaram o facto das estruturas factoriais estarem de acordo com as dimensões obtidas, tanto pelos autores dos instrumentos, como pelos estudos subsequentes de adaptação (ver Carron et al., 1998; Cruz \& Antunes, 1997; Gomes, 2005; Gomes \& Cruz, 2006a; Leitão, 1999). Paralelamente, deve ser registado o facto dos índices de fidelidade das subescalas serem muito positivos (quinze das subescalas encontram-se acima de .70). A excepção a esta regra prende-se fundamentalmente com duas dimensões, nomeadamente o "laissez-faire" da EMLD (comportamentos actuais) com .67, mas mesmo assim bastante próximos do valor de .70 aconselhado por Nunnally (1978) e o valor de .60 da atracção individual para o grupo (social). Neste último caso, o valor de "alpha" verificado reflecte as dificuldades sentidas pelos próprios autores do instrumento (ver Carron \& Spink, 1992; Carron et al., 1985) que também obtiveram indicadores abaixo de .70. De qualquer modo, o valor de .60 observado encontra-se dentro da margem dos resultados assinalados por Lowenthal (2001) como sendo passível de aceitação, embora assumindo um certo carácter indesejável. Assim sendo, todas as variáveis foram mantidas nas análises comparativas que se seguem, devendo-se no entanto ter em atenção aos resultados relativos na subescala da atracção individual para o grupo (social) pelas dificuldades referidas.

\section{Valores Médios das Variáveis em Análise}

Na Tabela 1 são apresentados a média, desvio padrão e valores mínimos e máximos obtidos em cada uma das dimensões dos três instrumentos de avaliação. Tal como se poderá verificar, existe uma grande semelhança entre as subescalas dos comportamentos actuais e preferidos na EMLD, sendo a motivação/inspiração a área mais frequente e valorizada pelos atletas, seguida do "feedback" positivo e negativo. Nas três facetas seguintes da EMLD, o aspecto mais interessante a registar prende-se com o facto da avaliação dos comportamentos democráticos assumidos pelos treinadores ser a dimensão menos frequente na EMLD (comportamentos actuais) e passar para a quarta mais valorizada pelos atletas na EMLD (comportamentos preferidos). Para além desta análise mais centrada no "ranking" de importância de cada uma das subescalas da EMLD, testámos a hipótese de existirem diferenças significativas entre os comportamentos actuais dos treinadores e os preferidos pelos atletas. Neste caso, e recorrendo a " $t$-testes" para amostras relacionadas, constatámos diferenças significativas em cinco facetas da escala: na motivação/inspiração $(t=-5.15, p<.001)$, no "feedback" positivo ( $t=-2.94$, $p<.01)$, no "feedback" negativo ( $t=-2.40, p<.05)$, no apoio social $(t=-3.81, p<.001)$ e no comportamento democrático $(t=-8.04, p<.001)$. Assim sendo, e exceptuando o factor "laissez-faire" onde não se registaram diferenças significativas, podemos afirmar que a vontade dos atletas em terem mais comportamentos por parte dos treinadores do que aqueles que recebem efectivamente adquire uma relevância estatística, sendo esta divergência particularmente evidente no comportamento democrático, na motivação/ inspiração e no apoio social (maiores valores de " $t$ " e de significância estatística).

Quanto à coesão, observa-se que o envolvimento pessoal dos atletas nas actividades sociais das equipas é a faceta mais prevalente, seguida depois pela atracção relativamente às tarefas a realizar pelas equipas. Com valores inferiores, aparecem as duas dimensões da integração na tarefa e no social.

Na satisfação, pode-se concluir que são os aspectos relativos ao bom ambiente e apoio existentes nas equipas que suscitam maior satisfação nos atletas, seguida das experiências positivas relacionadas com a liderança exercida pelos treinadores e, por último, a satisfação com o rendimento individual de cada atleta.

\section{Definição dos Grupos de Comparação}

$\mathrm{O}$ estudo das diferenças entre os atletas participantes neste estudo foi efectuado através de três grandes agrupamentos. Assim, no primeiro caso dividimos a amostra entre homens e mulheres da modalidade de futsal e testamos a hipótese da existência de diferenças ao nível da liderança (comportamentos actuais e preferidos), da coesão e da satisfação. De realçar, que esta restrição ao futsal prendese com o facto de, na nossa amostra, as participantes do sexo feminino serem apenas desta modalidade, fazendo por isso mais sentido compará-las com os seus colegas homens do mesmo desporto. Numa segunda possibilidade, anali- 
Psicologia: Reflexão e Crítica, 21(3), 482-491.

Tabela 1

Estatísticas Descritivas das Dimensões de Liderança, Coesão e Satisfação (Amostra Total)

\begin{tabular}{|c|c|c|c|c|}
\hline Variável & $M$ & $D P$ & Min. & Máx. \\
\hline \multicolumn{5}{|l|}{ LIDERANÇA (EMLD - Comportamentos actuais) } \\
\hline Motivação/inspiração & 3.44 & .88 & 1 & 5 \\
\hline "Feedback" positivo & 3.43 & .95 & 1 & 5 \\
\hline "Feedback" negativo & 2.60 & 1.04 & 1 & 5 \\
\hline Apoio social & 2.24 & .91 & 1 & 5 \\
\hline "Laissez-faire" & 2.19 & .89 & 1 & 5 \\
\hline Democrático & 2.11 & 1.00 & 1 & 5 \\
\hline \multicolumn{5}{|c|}{ LIDERANÇA (EMLD - Comportamentos preferidos) } \\
\hline Motivação/inspiração & 3.79 & .96 & 1 & 5 \\
\hline "Feedback" positivo & 3.68 & .92 & 1 & 5 \\
\hline "Feedback" negativo & 2.76 & 1.09 & 1 & 5 \\
\hline Democrático & 2.66 & 1.08 & 1 & 5 \\
\hline Apoio social & 2.47 & .95 & 1 & 5 \\
\hline "Laissez-faire" & 2.24 & .99 & 1 & 5 \\
\hline \multicolumn{5}{|l|}{$C O E S \tilde{A} O(Q C E D)$} \\
\hline Atracção indiv. para o grupo - social & 7.16 & 1.90 & 1 & 9 \\
\hline Atracção indiv. para o grupo - tarefa & 6.97 & 1.93 & 1 & 9 \\
\hline Integração no grupo - tarefa & 6.90 & 1.86 & 1 & 9 \\
\hline Integração no grupo - social & 6.23 & 2.27 & 1 & 9 \\
\hline \multicolumn{5}{|l|}{ SATISFAÇÃO $(E S)$} \\
\hline Satisfação com o ambiente e apoio na equipa & 5.93 & 1.17 & 1 & 7 \\
\hline Satisfação com a liderança & 5.49 & 1.47 & 1 & 7 \\
\hline Satisfação com o rendimento individual & 5.17 & 1.48 & 1 & 7 \\
\hline
\end{tabular}

samos as eventuais diferenças nas variáveis de liderança (comportamentos actuais e preferidos), coesão e satisfação de acordo com o escalão competitivo dos atletas (desde os infantis até aos seniores). Em terceiro lugar, observamos as possíveis diferenças percepcionadas pelos atletas em cada um dos escalões em termos dos comportamentos preferidos e actuais assinalados aos respectivos treinadores.

De salientar que esta divisão por várias categorias colocou alguns dos grupos em comparação com menos de 20 atletas, levando-nos por isso a optar pela utilização de medidas não-paramétricas, uma vez que são as mais aconselhadas nestas situações. Nos casos onde os sub-grupos criados não implicaram reduções significativas no total de atletas, procedemos como habitualmente com medidas paramétricas.

Diferenças na Liderança, Coesão e Satisfação em Função do Sexo e Escalão Competitivo dos Atletas

Começando pelas diferenças de sexo, e tendo por base os resultados do teste de Mann-Whitney (“U”), verificou-se que as mulheres percepcionaram mais comportamentos de "feedback" negativo ( $\mathrm{U}=216,5, p<.05)$ e menos comportamentos de "feedback" positivo na EMLD (comportamentos actuais) $(\mathrm{U}=198,5, p<.05)$. Por contraponto, os homens manifestaram uma maior preferência por comportamentos democráticos por parte dos respectivos treinadores $(U=199,5$, $p<.05)$. Ao nível da coesão, apesar das atletas terem evidenciado maiores níveis de união nas quatro dimensões avaliadas pelo QCED do que os seus colegas homens, em termos de diferenças significativas há a registar os aspectos sociais, tanto ao nível da integração $(U=166,5, p<.01)$ como da atracção individual para o grupo $(U=173,0, p<.01)$. No que respeita à satisfação, nenhuma das dimensões avaliadas pela Escala de Satisfação revelou diferenças significativas entre ambos os sexos.

Quanto à comparação entre os cinco escalões desportivos dos atletas participantes neste estudo (infantis, iniciados, juvenis, juniores e seniores), utilizámos análises de variância "One-way" (ANOVA), seguidas de comparações "post-hoc" com o teste de "Scheffé".

Relativamente à escala de liderança (EMLD, comportamentos actuais) constatámos diferenças em cinco das subescalas: motivação/inspiração $(F=7.22, p<.001)$, comportamentos democráticos $(F=7.33, p<.001)$, apoio social $(F=4.86, p<.01)$, "feedback" negativo $(F=3.69, p<.01) \mathrm{e}$ "laissez-faire" $(F=5.31, p<.001)$. Os resultados "post-hoc" permitiram-nos observar as seguintes diferenças entre os escalões: os iniciados e juniores percepcionaram menos 
comportamentos de motivação/inspiração do que os seniores; os iniciados e os juvenis assinalaram menos comportamentos democráticos do que os seus colegas infantis e seniores; os infantis apresentaram maiores níveis de apoio social do que atletas iniciados e juniores; os infantis apontaram maiores níveis de "feedback" negativo aos seus treinadores do que os seniores; os infantis manifestaram maior evitamento no exercício da liderança ("laissez-faire") do que os seniores.

Continuando ainda no domínio da liderança, mas reportando agora à EMLD (comportamentos preferidos), devemos assinalar diferenças em três das subescalas: apoio social $(F=3.77, p<.01)$, "feedback" negativo $(F=2.52$, $p<.05)$ e "laissez-faire" $(F=5.94, p<.001)$. De acordo com o teste "post-hoc" de "Scheffé", verificou-se que os infantis preferem mais comportamentos de apoio social por parte dos treinadores do que os seus colegas juniores; os infantis referiram maior preferência por comportamentos de "feedback" negativo que os seniores; e ao nível dos comportamentos de "laissez-faire" as diferenças indicam no sentido dos infantis apresentarem uma maior preferência neste domínio do que os iniciados, juniores e seniores.

No que respeita à coesão, duas dimensões apresentaram diferenças entre os vários escalões desportivos. Mais concretamente, é de registar valores significativos ao nível da atracção individual para o grupo ao nível social $(F=3.99$, $p<.05)$ bem como ao nível da integração no grupo tarefa $(F=2.54, p<.05)$. De acordo com o teste de "Scheffé", os iniciados apresentaram menores níveis de atracção individual para o social do que os juvenis e os juniores e, por outro lado, os iniciados assumiram menores níveis de integração na tarefa do que os seniores.

Quanto à escala de satisfação, é de assinalar diferenças ao nível da satisfação com a liderança $(F=7.23, p<.001)$, verificando-se pelo teste de "post-hoc" que os infantis evidenciaram maior satisfação com o treinador do que os iniciados e juniores e, por outro lado, os juniores assumiram menor satisfação nesta dimensão da satisfação do que os seus colegas mais velhos do escalão sénior.

No último conjunto de análises, testámos as diferenças nas dimensões dos comportamentos actuais e preferidos da EMLD em cada um dos escalões (teste de Wilcoxon - " $Z$ "). Neste caso, procurámos verificar a existência de discrepâncias em cada uma das equipas entre os comportamentos que os atletas percepcionaram nos treinadores e aqueles que seriam da sua maior preferência. Assim sendo, e começando pelos escalões de futebol, nos infantis há que registar diferenças em duas dimensões, nomeadamente o facto de preferirem mais comportamentos democráticos do que os que recebem por parte dos treinadores $(Z=-2.94$, $p<.01)$ e, curiosamente, também registarem uma maior preferência por comportamentos de "feedback" negativo do que os que são assumidos pelos treinadores $(Z=-1.97$, $p<.05)$. No escalão seguinte (iniciados), existem quatro áreas da liderança com discrepâncias, constatando-se que estes atletas preferem mais comportamentos do que os que são efectivamente demonstrados pelos treinadores ao nível da motivação/inspiração $(Z=-2.94, p<.01)$, dos comporta- mentos democráticos $(Z=-4.04, p<.001)$, do apoio social $(Z=-2.97, p<.01)$ e, uma vez mais, do "feedback" negativo $(Z=-1.98, p<.05)$. Para os juvenis, as diferenças fizeram-se sentir em duas áreas da liderança, verificando-se que estes atletas preferem mais comportamentos de motivação/inspiração $(Z=-2.41, p<.05)$ e democráticos $(Z=-3.75, p<.001)$ do que os que são realmente evidenciados pelo treinador. Este padrão de resultados é igualmente observado no escalão seguinte (juniores), sendo também os comportamentos de motivação/inspiração $(Z=-2.82, p<.001)$ e os democráticos $(Z=-3.35, p<.001)$ que registaram diferenças estatisticamente significativas, ou seja, estes atletas gostariam de ver no seu treinador uma maior frequência de acções nestes dois domínios. Quanto aos seniores, constatámos uma grande semelhança entre os comportamentos actuais do treinador e os preferidos pelos atletas, não havendo a assinalar desigualdades de relevo do ponto de vista estatístico.

Já para a modalidade de futsal, optámos por manter a mesma lógica individualizada nas análises e, por isso, repartimos a observação das eventuais diferenças nos dois escalões existentes (juniores e seniores) e nas diferenças de sexo (masculino e feminino). Deste modo, no escalão júnior do sexo feminino, apenas uma das variáveis apresentou valores de relevo, constatando-se uma maior preferência por comportamentos democráticos do que os que são demonstrados pelo treinador $(Z=-2.16, p<.05)$. Exactamente no mesmo sentido parecem ir os resultados das suas colegas do mesmo sexo do escalão seguinte, apontando também ao respectivo treinador uma maior vontade em participarem na tomada de decisão $(Z=-2.00, p<.05)$. Quanto aos homens, curiosamente também existe um acordo na dimensão de liderança, pois tanto os atletas incluídos no escalão júnior como nos seniores apontaram uma maior preferência por comportamentos de motivação/ inspiração $(Z=-2.32, p<.05$ e $Z=-2.15, p<.05$, respectivamente).

\section{Discussão}

Em tão poucos contextos como o desportivo assistimos à influência exercida pelos líderes na acção das respectivas equipas, sendo verdadeiramente notável o facto de tantos indivíduos (crianças, jovens e adultos) se submeterem, de um modo voluntário, à acção de uma única pessoa: o treinador (Chelladurai, 1984; Cruz \& Gomes, 1996). Este trabalho procura ajudar a compreender quais os factores que podem contribuir para a explicação desta situação, observando a forma como os treinadores são percepcionados pelos atletas e a relação entre algumas variáveis pessoais e desportivas dos praticantes e os níveis de coesão e satisfação.

Um primeiro aspecto a referir, prende-se com a análise das características psicométricas dos instrumentos utilizados que, de um modo geral, reflectiram as estruturas factoriais propostas pelos seus autores e apresentaram bons índices de validade e fidelidade. Talvez a única excepção a este padrão seja mesmo a escala de coesão, que poderá beneficiar de uma reflexão acerca dos itens que compõem 
algumas das subescalas, principalmente as relativas à atracção individual para a tarefa e para o social, uma vez que este estudo confirma as dificuldades encontradas noutras investigações (ver Carron \& Spink, 1992; Carron et al., 1985; Cruz \& Antunes, 1997; Gomes, 2005).

Quanto aos valores globais das várias subescalas dos instrumentos, deve ser salientado o facto da motivação/ inspiração representar a dimensão mais prevalente da acção dos treinadores, sendo o comportamento mais percepcionado e preferido pelos atletas. Este resultado corrobora os valores encontrados por Gomes (2005) e confirma a importância desta dimensão, baseada nas abordagens carismáticas e transformacional, na compreensão do exercício da liderança em contextos desportivos. Com valores globais inferiores aparecem os comportamentos de "feedback" positivo e negativo, tanto ao nível dos comportamentos actuais como ao nível dos preferidos. Ao verificarmos um acordo entre estas três áreas de acção (motivação/inspiração, "feedback" positivo e negativo), tanto na percepção dos comportamentos actuais como dos preferidos, pode-se afirmar que os treinadores avaliados pelos atletas deste estudo terão a ganhar ao aumentarem mais estas facetas da sua acção. O que é curioso é a inclusão do "feedback" negativo como um dos comportamentos preferidos pelos atletas, ocupando a terceira posição, atrás do "feedback" positivo e da motivação/inspiração. Que seja do nosso conhecimento, este resultado não tem sido muito apontado noutros estudos, existindo precisamente indicações no sentido contrário, ou seja, o facto dos praticantes preferirem mais comportamentos de treino e instrução, "feedback" positivo e democráticos por parte dos técnicos, principalmente à medida que aumenta o sucesso desportivo dos atletas (ver Chelladurai, 1990, 1993b; Gomes \& Cruz, 2006c).

Um outro aspecto a salientar, é o facto de em todas as áreas de acção dos treinadores, aquela onde se registam maiores divergências entre os comportamentos actuais e os preferidos pelos atletas ser o comportamento democrático que, curiosamente, é ainda menos manifestado pelos treinadores do que o "laissez-faire". Neste sentido, uma das constatações mais interessantes deste trabalho prendese com o facto dos atletas do futebol e futsal percepcionarem uma baixa vontade dos seus treinadores em auscultarem as suas opiniões e possibilitar-lhes alguma intervenção no processo de tomada de decisão. Além disso, estes resultados não confirmam outros estudos que apontam uma menor preferência por parte dos atletas de modalidades colectivas pelos comportamentos democráticos, parecendo valorizar uma menor participação na tomada de decisão, principalmente quando são comparados com outros atletas de modalidades individuais (ver Chelladurai, 1978; Terry \& Howe, 1984).

Ainda dentro desta análise das frequências globais das subescalas, os valores encontrados ao nível da coesão e da satisfação reproduzem exactamente a mesma ordem encontrada por Gomes (2005) com atletas portugueses de várias modalidades. De facto, os aspectos relacionados com o envolvimento pessoal, tanto ao nível social como da ta- refa, são os que mais se salientam, seguindo-se a percepção acerca da união na equipa, como um todo, em termos das tarefas e actividades sociais a realizar. Do mesmo modo, os atletas evidenciaram um maior bem-estar relativamente ao ambiente positivo e de apoio existente nas equipas, seguindo-se a satisfação com a liderança e, por fim, a satisfação com o rendimento individual. Neste último caso, o facto dos atletas deste estudo serem praticantes de modalidades colectivas poderá ajudar a compreender o maior interesse pelos aspectos sociais e bom relacionamento entre todos, em detrimento dos factores mais ligados ao rendimento individual.

Observando agora as diferenças entre os atletas em função do sexo, há que destacar dois aspectos. Por um lado, os homens assumiram um maior desejo em participarem no processo de tomada de decisão do que as mulheres. No entanto, e considerando as análises das diferenças entre os comportamentos preferidos e actuais dos treinadores, também as atletas do sexo feminino (juniores e seniores) assumiram um maior interesse pela partilha do poder por parte dos técnicos. Estes resultados reforçam os dados de outras investigações que salientam a necessidade do envolvimento dos atletas na definição de aspectos importantes relacionados com o funcionamento das respectivas equipas (ver Chelladurai \& Arnott, 1985, Chelladurai \& Saleh, 1978). Por outro lado, a divergência entre o "feedback" positivo (mais referido pelos homens) e o "feedback" negativo (mais referido pelas mulheres) deverá merecer a atenção por parte dos responsáveis técnicos, pois as indicações da investigação demonstram consequências mais nefastas sobre a satisfação dos atletas quando quem lidera não assume os níveis de reforço e reconhecimento desejados pelos atletas (ver Chelladurai, 1984; Gomes, 2005; Horne \& Carron, 1985; Riemer \& Chelladurai, 1995; Weiss \& Friedrichs, 1986).

Uma outra variável em análise neste trabalho prendeuse com as eventuais diferenças na percepção dos estilos de liderança, satisfação e coesão ao longo dos vários escalões competitivos, equivalendo, na prática, a uma observação das diferenças em função da idade dos praticantes. Começando pelas dimensões de motivação/inspiração e comportamento democrático da EMLD, verificou-se que os iniciados, juvenis e juniores percepcionam menos comportamentos nestas áreas do que os seus colegas seniores (em ambos as facetas) e os infantis (no caso do comportamento democrático). Já ao nível do apoio social, são os mais jovens (infantis), por comparação aos iniciados e seniores, que assinalam uma maior preocupação dos treinadores com os aspectos pessoais. Este padrão de diferenciação inverte-se nas acções mais negativas dos treinadores, pois os infantis relataram maior prevalência de "feedback" negativo e "laissez-faire" aos seus treinadores. É curioso assinalar que é precisamente este escalão mais novo (infantis) que mais divergências evidencia com os outros atletas ao nível da EMLD (comportamentos preferidos) relatando uma maior vontade em ter apoio social, "feedback" negativo (!) e "laissez-faire". Os dados na literatura neste domínio não abundam, exceptuando as indicações fornecidas por Chelladurai e Kuga (1996) de que os atletas mais novos e 
em fase de aprendizagem parecem preferir estilos de liderança mais centrados na relação e à medida que vão ficando mais experientes começam a valorizar a liderança centrada na tarefa. Neste mesmo sentido, Fonseca e Fonseca (1997) constataram que os atletas juniores de seis equipas de futebol portuguesas parecem apontar o comportamento de treino e instrução (acções mais centradas na execução das tarefas) como o mais prevalente das acções dos treinadores. Do nosso estudo, resulta principalmente a indicação de que os atletas no último escalão (seniores) parecem ser aqueles que melhor avaliam os respectivos treinadores, pois apontam-lhes maiores níveis de motivação/ inspiração, maior possibilidade de envolvimento na tomada de decisão e, pelo contrário, menor prevalência de "feedback" negativo e "laissez-faire". Um outro dado a reter, relaciona-se com o facto dos atletas mais novos (infantis) desejarem maior apoio social e "laissez-faire" por parte dos treinadores. Menos sentido, mas necessitando de confirmação por parte da investigação futura, parece ser a tendência destes atletas preferirem mais comportamentos de "feedback" negativo que, obviamente, não são indicados na promoção de ambientes desportivos propícios à iniciação e formação desportiva de crianças e jovens (Gomes, 1997, 2001; Martens, 1980, 1996). Em termos da coesão e satisfação, os aspectos mais evidentes prendem-se com o facto dos níveis de coesão (tanto ao nível social como da tarefa) parecerem aumentar com a idade dos atletas (principalmente nos juniores e seniores) e o facto dos mais novos (infantis) e mais velhos (seniores) serem aqueles evidenciaram maior satisfação com a liderança dos respectivos treinadores.

Por último, no que respeita à observação das diferenças entre os comportamentos actuais e preferidos da EMLD em cada uma das equipas deste estudo, devemos realçar alguns aspectos fundamentais. Desde logo, a maior preferência pelo "feedback" negativo encontrado nos atletas infantis e iniciados devem, como referimos, ser objecto de confirmação por estudos futuros, pois representam um padrão que não era espectável, nem do nosso conhecimento. Em segundo lugar, e assumindo um carácter mais evidente e esperado, é o facto de em todas as equipas deste estudo se observar uma maior vontade por parte dos atletas em verem os respectivos treinadores assumirem mais comportamentos de motivação/inspiração e democráticos (em todas as equipas do futebol aparecem estas duas facetas e nas do futsal apenas uma). Estes resultados confirmam, do nosso ponto de vista, duas implicações práticas fundamentais para o trabalho dos treinadores na orientação das equipas. Por um lado, a importância de se assumirem como figuras transformacionais, dirigindo as suas acções para a motivação dos atletas, promovendo o desejo de sucesso e esforço contínuo e, paralelamente, procurarem representar modelos a seguir, em termos de optimismo, confiança e respeito. Por outro lado, devem considerar a possibilidade de negociarem e discutirem mais com os atletas aspectos fundamentais do funcionamento das equipas (comportamento democrático). Na realidade, e segundo a opinião dos atletas deste estudo, a dimensão democrática é uma das menos evidentes na acção diária dos treinadores, apesar de ser uma das mais valorizadas pelos membros da equipa. Estes dados são tão mais relevantes se atendermos a um dos pressupostos centrais do modelo de Chelladurai $(1978,1984)$, onde se afirma que quanto mais congruente é o estilo de liderança dos treinadores com aquilo que os atletas preferem e percepcionam, melhor é a avaliação que estes fazem do responsável técnico, assim como o tipo de atitudes que manifestam relativamente a ele.

Em síntese, os resultados agora encontrados demonstram a necessidade dos treinadores ajustarem os seus comportamentos aos atletas que orientam, uma vez que o tipo de escalão e o sexo dos praticantes implicou discrepâncias na avaliação do exercício da liderança bem como na coesão e satisfação manifestada pelos atletas relativamente à prática desportiva. Apesar destas diferenças importantes, também foi evidente neste estudo que algumas dimensões positivas da acção dos treinadores, como a motivação/inspiração, "feedback" positivo e comportamento democrático, parecerem reunir uma maior unanimidade nas preferências manifestadas pelos praticantes. Neste sentido, ganha sustentação a ideia de que ser eficaz como treinador resulta de uma conjugação entre aquilo que o técnico é como pessoa (e.g., objectivos pessoais e profissionais, disponibilidade para ajudar os outros, etc.), o tipo de atletas que orienta (e.g., sexo, idade, preferências pessoais, etc.) e o contexto onde exerce as suas funções (e.g., modalidade colectiva ou individual, escalão competitivo, etc.).

É neste sentido que a investigação futura deverá ser conduzida, estudando as dimensões da acção dos treinadores que melhor explicam o sucesso nesta classe profissional e que mais se relacionam com o rendimento desportivo e satisfação dos atletas.

\section{Referências}

Avolio, B. J., \& Bass, B. M. (1988). Transformational leadership, charisma and beyond. In J. Hunt, H. R. Baliga, H. P. Dachler, \& C. A. Schriesheim (Eds.), Emerging leadership vistas. Lexington, MA: D. C. Heath.

Bass, B. M. (1985). Leadership and performance beyond expectations. New York: Free Press.

Bass, B. M. (1990). Bass and Stogdill's handbook of leadership $\left(3^{\text {rd }}\right.$ ed.). New York: Free Press.

Bass, B. M., \& Avolio, B. J. (1997). Full Range leadership development: Manual for the Multifactor Leadership Questionnaire. Palo Alto, CA: Mind Garden.

Brawley, L. R., Carron, A. V., \& Widmeyer, W. N. (1987). Assessing the cohesion of teams: Validity of the group environment questionnaire. Journal of Sport Psychology, 9, 275-294.

Brown, F. W., \& Dodd, N. G. (1999). Rally the troops or make the trains run on time: The relative importance and interaction of contingent reward and transformational leadership. Leadership and Organization Development Journal, 20, 291299.

Burns, J. M. (1978). Leadership. New York: Harper \& Row.

Carron, A. V., Brawley, L. R., \& Widmeyer, W. N. (1998). The measurement of cohesiveness in sport groups. In J. L. Duda (Ed.), Advances in sport and Exercise Psychology measurement (pp. 213-226). Morgatown, PA: Fitness Information Technology. 
Carron, A. V., \& Spink, K. S. (1992). Team building in an exercise setting. The Sport Psychologist, 7, 8-18.

Carron, A. V., Widmeyer, W. N., \& Brawley, L. R. (1985). The development of an instrument to assess cohesion in sport teams: The group environment questionnaire. Journal of Sport and Exercise Psychology, 7, 244-266.

Chelladurai, P. (1978). A contingency model of leadership in athletics. Unpublished doctoral dissertation, University of Waterloo, Canada.

Chelladurai, P. (1984). Leadership in sports. In J. M. Silva \& R. S. Weinberg (Eds.), Psychological foundations of sport (pp. 329-339). Champaign, IL: Human Kinetics.

Chelladurai, P. (1990). Leadership in sports: A review. International Journal of Sport Psychology, 21, 328-354.

Chelladurai, P. (1993a). Leadership. In R. N. Singer, M. Murphey, \& L. K. Tennant (Eds.), Handbook of research on Sport Psychology (pp. 647-671). New York: Macmillan.

Chelladurai, P. (1993b). Styles of decision making in coaching. In J. M. Williams (Ed.), Applied Sport Psychology. Personal growth to peak performance ( $2^{\text {nd }}$ ed., pp. 99-109). Mountain View, CA: Mayfield.

Chelladurai, P., \& Arnott, M. (1985). Decision styles in coaching: Preferences of basketball players. Research Quarterly for Exercise and Sport, 56, 15-24.

Chelladurai, P., Imamura, H., Yamaguchi, Y., Oinuma, Y., \& Miyauchi, T. (1988). Sport leadership in a cross-national setting: The case of Japanese and Canadian University athletes. Journal of Sport and Exercise Psychology, 10, 374-389.

Chelladurai, P., \& Kuga, D. J. (1996). Teaching and coaching: Group and task differences. Quest, 48, 470-485.

Chelladurai, P., \& Saleh, S. D. (1978). Preferred leadership in sports. Canadian Journal of Applied Sport Sciences, 3, 85-92.

Chelladurai, P., \& Saleh, S. D. (1980). Dimensions of leader behavior in sports: Development of a leadership scale. Journal of Sport Psychology, 2, 34-45.

Conger, J. A., \& Kanungo, R. (1998). Charismatic leadership in organizations. London: Sage.

Cruz, J. F., \& Antunes, J. (1997). Adaptação e características psicométricas do "questionário de coesão desportiva" e da "escala de satisfação com a competição". In J. F. Cruz \& A. R. Gomes (Eds.), Psicologia aplicada ao desporto e à actividade física: Teoria, investigação e intervenção (pp. 339-348). Braga, Portugal: Associação dos Psicólogos Portugueses.

Cruz, J. F., \& Gomes. A. R. (1996). Liderança de equipas desportivas e comportamento do treinador. In J. F. Cruz (Ed.), Manual de Psicologia do Desporto (pp. 389-409). Braga, Portugal: Sistemas Humanos e Organizacionais.

Cruz, J. F., \& Viana, M. F. (1993). Questionário de Coesão em Equipas Desportivas (QCED-GEQ). Manuscrito não publicado, Instituto de Educação e Psicologia, Universidade do Minho, Braga, Portugal.

Doherty, A. J. (1997). The effect of leader characteristics on the perceived transformational/transactional leadership and impact of interuniversity athletic administrators. Journal of Sport Management, 11, 275-285.

Fonseca, P. M., \& Fonseca, A. M. (1997). Os comportamentos de liderança no futebol junior de competição. In J. F. Cruz \& A. R. Gomes (Eds.), Psicologia aplicada ao desporto e à actividade física: Teoria, investigação e intervenção (pp. 359-365). Braga, Portugal: Associação dos Psicólogos Portugueses.

Gomes, A. R. (1997). Aspectos psicológicos da iniciação e formação desportiva: O papel dos pais. In J. F. Cruz \& A. R. Gomes (Eds), Psicologia aplicada ao desporto e actividade física: Teoria, investigação e intervenção (pp. 291-319). Braga, Portugal: Associação dos Psicólogos Portugueses. Retrieved April 02, 2007, from http://hdl.handle.net/1822/5337
Gomes, A. R. (2001). A promoção da comunicação entre treinadores e pais na iniciação e formação desportiva de crianças e jovens. Treino Desportivo, 1, 30-37. Retrieved April 10, 2007, from http://hdl.handle.net/1822/4417

Gomes, A. R. (2005). Liderança e relação treinador-atleta em contextos desportivos. Tese de Doutorado não-publicada, Universidade do Minho, Braga, Portugal. Retrieved April 22, 2007, from http://hdl.handle.net/1822/3334

Gomes, A. R., \& Cruz, J. F. (2006a). Relação treinador-atleta: Desenvolvimento de um instrumento de avaliação dos estilos de liderança. In C. Machado, L. Almeida, M. Gonçalves, M. Adelina, \& V. Ramalho (Eds.), Actas da XI Conferência Internacional de Avaliação Psicológica: Formas e contextos (pp. 1037-1046). Braga, Portugal: Psiquilíbrios. Retrieved May 12, 2007, from http://hdl.handle.net/1822/5829

Gomes, A. R., \& Cruz, J. F. (2006b). Relação treinador-atleta e exercício da liderança no desporto: A percepção de treinadores de alta competição. Estudos de Psicologia (Natal), 11, 5-15. Retrieved April 11, 2007, from http://hdl.handle. net/1822/6348

Gomes. A. R., \& Cruz, J. F. (2006c). Estilos de liderança, coesão e satisfação no desporto: Análise das diferenças em função do tipo de modalidade praticada e do sucesso desportivo obtido pelos atletas. In N. Santos, M. Lima, M. Melo, A. Candeias, M. Grácio, \& A. Calado (Eds.), Actas do VI Simpósio Nacional de Investigação em Psicologia (Vol. 11, pp. 103-123). Évora, Portugal: Universidade de Évora. Retrieved March 27, 2007, from http://hdl.handle.net/1822/5985

Gomes, A. R., Sousa, S. A., \& Cruz, J. F. (2006). Charismatic, transformational and visionary dimensions in sport leadership: Toward news paths for the study of coach-athletes relationships. In N. S. Huber \& M. Harvey (Eds.), Leadership at the crossroads (pp. 84-94). Baltimore, MD: University of Maryland. Retrieved March 16, 2007, from http:// hdl.handle.net/1822/6349

Gorsuch, R. L. (1983). Factor analysis ( $2^{\text {nd }}$ ed.). Hillsdale, NJ: Erlbaum.

Hair, J., Anderson, R., Tatham, R., \& Black, W. (1995). Multivariate data analysis with readings $\left(4^{\text {th }}\right.$ ed.). Upper Saddle, NJ: Prentice-Hall.

Hawkins, K., \& Tolzin, A. (2002). Examining the team/leader interface: Baseball teams as exemplars of postmodern organizations. Group and Organization Management, 27, 97-112.

Horne, T., \& Carron, A. V. (1985). Compatibility in coach-athlete relationships. Journal of Sport Psychology, 7, 137-149.

House, R. J., \& Shamir, B. (1993). Toward the integration of transformational, charismatic, and visionary theories. In M. M. Chemers \& R. Ayman (Eds.), Leadership theory and research: Perspectives and directions (pp. 81-107). San Diego, CA: Academic Press.

Leitão, J. C. (1999). A relação treinador-atleta: Percepção dos comportamentos de liderança e de coesão em equipas de futebol. Tese de Doutorado não-publicada, Universidade de Coimbra, Portugal.

Lowenthal, K. M. (2001). An introduction to psychological tests and scales. Cornwall, UK: Psychology Press.

Martens, R. (1980). The uniqueness of the young athlete: Psychological considerations. American Journal of Sports Medicine, 8, 382-385.

Martens, R. (1996). Turning kids on to physical activity for a lifetime. Quest, 48, 303-310.

Nunnally, J. C. (1978). Psychometric theory. New York: McGrawHill Book. 
Gomes, A. R., Pereira, A. P. \& Pinheiro, A. R. (2008). Liderança, Coesão e Satisfação em Equipas Desportivas: Um Estudo com Atletas Portugueses de Futebol e Futsal.

Podsakoff, P. M., MacKenzie, S. B., Moorman, R. H., \& Fetter, R. (1990). Transformational leader behaviors and their effects on followers trust in leader, satisfaction, and organizational citizenship behaviors. Leadership Quarterly, 1, 107-142.

Riemer, H. A., \& Chelladurai, P. (1995). Leadership and satisfaction in athletics. Journal of Sport and Exercise Psychology, 17, 276-293.

Terry, P. C., \& Howe, B. L. (1984). Coaching preferences of athletes. Canadian Journal of Applied Sport Sciences, 9, 188193.

Weiss, M. R., \& Friedrichs, W. D. (1986). The influence of leader behaviors, coach attributes, and institutional variables on performance and satisfaction of collegiate basketball teams. Journal of Sport Psychology, 8, 332-346.

Widmeyer, W. N., Brawley, L. R., \& Carron, A. V. (1985). The measurement of cohesion in sport teams: The group environment questionnaire. London: Sports Dynamics.

Yusof, A. (1998). The relationship between transformational leadership behaviors of athletic directors and coaches“ job satisfaction. Physical Educator, 55, 170-176.

Zacharatos, A., Barling, J., \& Kelloway, E. K. (2000). Development and effects of transformational leadership in adolescents. Leadership Quarterly, 11, 211-227. 